\title{
Young children's understanding of violations of property rights
}

\author{
Federico Rossano ${ }^{\mathrm{a}, *}$, Hannes Rakoczy ${ }^{\mathrm{b}}$, Michael Tomasello $^{\mathrm{a}}$ \\ ${ }^{a}$ Max-Planck-Institute for Evolutionary Anthropology, 04103 Leipzig, Germany \\ ${ }^{\mathrm{b}}$ University of Göttingen, Institute of Psychology E Courant Research Centre, Evolution of Social Behaviour, Göttingen, Germany
}

\section{A R T I C L E I N F O}

\section{Article history:}

Received 25 October 2010

Revised 2 June 2011

Accepted 12 June 2011

Available online 19 July 2011

\section{Keywords:}

Norms

Property

Rights

Protest

\begin{abstract}
A B S T R A C T
The present work investigated young children's normative understanding of property rights using a novel methodology. Two- and 3-year-old children participated in situations in which an actor (1) took possession of an object for himself, and (2) attempted to throw it away. What varied was who owned the object: the actor himself, the child subject, or a third party. We found that while both 2- and 3-year-old children protested frequently when their own object was involved, only 3-year-old children protested more when a third party's object was involved than when the actor was acting on his own object. This suggests that at the latest around 3 years of age young children begin to understand the normative dimensions of property rights.
\end{abstract}

(c) 2011 Elsevier B.V. All rights reserved.

\section{Introduction}

Possession and property structure many, if not most, of our everyday interactions with objects. Young children (and even some animals) care about physical possession, and indeed many of children's early conflicts with peers are over physical possession (Bakeman \& Brownlee, 1982; Brenner \& Mueller, 1982; Bronson, 1975; Dawe, 1934; Dunn \& Munn, 1987; Hay, 1984; Hay \& Ross, 1982; Shantz, 1987). By around 24 months, young children can reliably identify who posseses familiar objects (Fasig, 2000), and their appropriate use of possessive language ("My milk", "Mommy's sock") suggests some nascent understanding even earlier than that (Hay, 2006; Tomasello, 1998).

But possession and property are quite different things: while possession can be understood as a natural relation of proximity, physical control, etc., of persons to objects, property is a social, normatively structured institution (Searle, 1995; Snare, 1972). The notion of property thus addresses not the relation of people to things, but rather the

\footnotetext{
* Corresponding author. Address: Max-Planck-Institute for Evolutionary Anthropology, Deutscher Platz 6, 04103 Leipzig, Germany. Tel.: +49 3413550 430; fax: +493413550444.

E-mail address: federico_rossano@eva.mpg.de (F. Rossano).
}

relation of people to people (their "agreements") with respect to things (Rose, 1985; Snare, 1972; for developmental aspects of this, see Kalish, 2005). Property is a status conferred on objects by the collective assignment of some social body who agrees to "respect" property assignments. Regarding its logical structure, "property" is a cluster concept, defined by a network of constitutive rules regulating (i) under which conditions who owns what (call them "conditions of ownership" rules), and (ii) what implications (rights, commitments, entitlements, etc.) owning which objects carries under which conditions (call them "implications of ownership" rules) (Snare, 1972). For example, buying an object, rather than renting it, is a proper condition of ownership, which then implies (entitles) that one may use it, sell it, give it to other people, destroy it, etc.

Some recent studies have begun to look at young children understanding of property as a social institution. Some studies have focused on how they infer ownership from hearing stories or seeing drawings of people acting with things (e.g., Friedman \& Neary, 2008; Neary, Friedman, \& Burnstein, 2009). These studies have focused on such things as first possession (e.g., who begins the story holding an object) or control of permission (e.g., who says whether others can use an object) as cues of ownership. Other studies have focused on children's ability to track 
and understand transfers of ownership (that is, "conditions of ownership") (e.g., Blake \& Harris, 2009; Kim \& Kalish, 2009). In most studies, children were told stories in which the ownership of some object changed (e.g., someone bought it) or physical possession changed from one individual to another without a change of ownership (e.g., someone borrowed or stole an object) and were then asked who the owner was in the end. From around 5 years of age, children have been found to deploy some understanding of ownership transfers, distinguishing for example, gift-giving from stealing (Blake \& Harris, 2009; for children's moral evaluation of theft, see e.g., Tisak \& Turiel, 1984). Similarly, in one recent study children directly participated in a situation pertaining to ownership (manipulations of objects by different actors), rather than hearing stories and seeing pictures about it (Kangiesser, Gjersoe, \& Hood, 2010). It was found that according to 3- and 4-year-olds, some manipulations of objects (investment of creative labor in somebody else's property) would lead to a transfer of the ownership of the object.

Relatively little work has looked at children's understanding of "implications of ownership" rules. Through observational data recorded in families' homes, Ross (1996) documented that in conflict among siblings (2 and 4 year old respectively), older children often invoke ownership rights during their disputes to justify their claims. Earlier work using a verbal interview methodology has focused on children's moral evaluation of actions on objects depending on their property status (Hook, 1993). This work failed to find competence in children before the age of around 10: Younger children did not differentiate in their normative evaluation between, e.g., destroying one's own object (permitted in terms of property rights) and destroying someone else's object (a transgression of property rights) (for children's moral evaluation of destruction of someone else's property, see also Vaish, Missana, \& Tomasello, 2011).

More recent work has not directly asked children to normatively evaluate different acts with objects depending on their property status, but has investigated children's understanding of "implications of ownership" rules by asking them questions as to what different people "should get to decide" with regard to different objects (e.g., how to use them, whether to destroy them etc.) as a function of their property status (Kim \& Kalish, 2009). Again, from around 5 years of age, children showed some understanding by privileging owners over non-owners in deciding about the fate of objects. What remains unclear from this study, however, is what, if anything, children understand about the normative structure and implications of "implications of ownership" rules. Do they understand that deviations from the rules are not only surprising but mistakes?

A different line of recent work has documented a nascent understanding of the normative implications of rules and status in another domain, the domain of games (Rakoczy, 2008; Rakoczy \& Tomasello, 2009; Rakoczy, Warneken, \& Tomasello, 2008, 2009; Wyman, Rakoczy, \& Tomasello, 2009). What is novel about these studies is the measure of normative awareness: rather than administering explicit interviews, children were confronted in an interactive paradigm with actions that did or did not respect the constitutive rules of a game and the status of objects therein. Both in games of pretence and in simple rules games, children from age 2 to 3 not only learned to play games according to their constitutive rules themselves, but spontaneously and actively enforced those rules towards third parties: They protested, criticized, and instructed wrongdoers in the case of actions violating an object's status in the context of the game. What such behavior clearly indicates is that children understand that the rules of games have normative force, and that this force applies in agent-neutral ways (e.g., Nagel, 1986) to all participants of the practice alike.

The crucial question for present purposes is now whether with such a new interactive measure of normative awareness, some nascent understanding of the normative implications of property as a status defined by rules can be shown already in early childhood. From a theoretical point of view, this question is interesting not only in its own right, but also in the broader context of children's developing understanding of institutional reality more generally (Kalish, 2005). It might be that games are special in that they are "non-serious" activities, and so the normative consequences of games only reach as far as the very limited game context. Property's status, in contrast is very serious, and its normative implications span basically our whole everyday life. Documenting that young children understand the normative structure of property as a normative status would thus amount to showing that their early normative awareness is genuine, not limited to the arguably special case of games.

In the present work, therefore, we adapted the measures previously used to study young children's understanding of normative issues involving games (spontaneous protest etc.) to issues involving property. We focused especially on children's understanding of "implications of ownership". All children thus watched as an actor (a) took possession of, and (b) attempted to dispose of the target object. What we varied was who owned this object: the actor himself, the child subject, or a third party. If children understand the normative structure of property, they should intervene in response to both kinds of actions if and only if the object does not belong to the actor (that is, both when it belongs to themselves and when it belongs to a third party). Such differential intervention would reflect an understanding of the agent-neutral normative structure of property in two ways: first, by not only respecting the rules oneself, but by enforcing them towards third parties; and second, by enforcing them regardless of whose rights are violated (first or third person). Two- to 3-year-old children were tested, as this is the age at which they show some normative awareness in the domain of game rules.

\section{Method}

\subsection{Participants}

Thirty 3-year-olds (34-38 months, mean age $=36$, 18 months; 15 boys, 15 girls) and thirty 2-year-olds (2428 months, mean age $=26,14$ months; 15 boys, 15 girls $)$ 
were tested. An additional seven children (four 2-year-olds and three 3-year-olds) were tested but excluded from the final sample because they were uncomfortable during the testing phase or prevented the experimenters from continuing testing (e.g., by grabbing the object belonging to them and refusing to let the experimenters touch it). The children were recruited from urban daycare centers, came from mixed socioeconomic backgrounds, and were native German speakers. The experiment was run in German.

\subsection{Materials and design}

In a within-subject design, each child was tested in three conditions, with two trials per condition. In each condition, a puppet performed actions on a target object, with the crucial difference between conditions being who owned the target object. The conditions were:

- Child: object owned by child.

- Third party: object owned by E2.

- Control: object owned by puppet herself.

All children first received a round of one trial per condition (order counterbalanced across subjects), and then a second round of trials (same order as in the first round). Two different types of objects would be used for each subject: one type (e.g., hats) would be used for the first round of trials (a different hat would be used for each condition) and a different type (e.g., jackets) would be used for the second round of trials (a different jacket would be used for each condition).

The target objects used were clothing objects. First, experimenters identified two pieces of clothing from the child that might be used, typically a cap or scarf or coat from the wardrobe at the kindergarten (pointed out to them by the child herself; if the child had none, something the child was already wearing was used). The similar clothing items used for E2 and the puppet were then introduced in the testing room. E2 would normally sit through the entire procedure wearing the clothes later used for the test (e.g., her hat) while the puppet would introduce the items belonging to him directly to the child.

\subsection{Procedure}

After identifying two pieces of the child's clothing to be used, the child and the experimenters entered the testing room and sat down at a table. The child was seated such that she had the first experimenter (E1), operating a hand puppet, on her right and E2 on her left. Before sitting, though, the experimenters would emphasize that there was trash on the table (consisting mainly of paper clips) and they asked the child to help clean up the table by putting the paper clips into the trash can, located on the right of the child (the rationale being that the child should get used to the trash can by throwing things away). Then the three of them played together until the child felt comfortable.

\subsubsection{Warm-up phase}

The experimenters then involved the child in some games in which the puppet made instrumental mistakes (e.g., the puppet would try to write on a piece of paper holding a pencil upside down). The rationale of these games was to familiarize children with the puppet and make them feel comfortable about intervening to correct his behavior. The four objects used to make instrumental mistakes were: a crayon, a pair of scissors, a music box and a broom. The puppet, e.g., would attempt to write on a piece of paper holding the crayon upside down and would repeat this action a few times showing surprise and frustration. If the child would not independently intervene either by correcting the puppet's action or by taking the object and showing him how to use it, E2 would ask the child whether she would know how to do it, to facilitate the child intervention. If the child would not intervene at all after three or four more attempts to write on the piece of paper, the puppet would stop using that object and proceed with the next one of the four listed above. E2 would not correct the puppet nor insist with the child, apart from the indirect suggestion mentioned above. There was no coaching of protest.

After this, an important prop to be used in the actual test trials was introduced: The puppet brought out a paper bag, showed it to the child and explained that it was his bag and that he puts in it the things that he wants to take home. While the child was distracted, E2 would put on the table, one at a time, one of four objects (a plastic carrot, a plastic apple, a rubber duck and a brush), then E2 would turn her back towards the table. This way the child would not assume that the objects that the puppet takes are owned by E2. The puppet, who was hiding under the table, would suddenly reappear and notice the presence of the object placed by E2 on the table. The puppet would ask the child what the object was and express a positive evaluation of it. Then he would put the bag on the table and claim the object for himself by putting it into his bag and saying "now this is mine". The rationale for this part was to introduce the bag to the child, so that any time the puppet would put the bag on the table while an object was lying on the table, the child could foresee the puppet's intention to take the object, put it into his bag and claim that it now belonged to him. Moreover, the aim was to create a situation similar to the one occurring in the testing phase by having the puppet reappearing, noticing the presence of an object on the table and claiming it for himself, assuming that it did not belong to anyone. The puppet was supposed to appear as a naïve character, who might not realize that some objects are owned by others and as such cannot be appropriated so easily. The fact that the puppet could do it four times in a row without sanctioning and with the above mentioned objects should help the child interpret the puppet's actions as naïve rather than mean.

\subsubsection{Test phase}

In the test phase, each child received six trials, two per condition. Each trial consisted of three phases: (i) presentation of the object and clarification of its property status; (ii) puppet takes away the object; (iii) puppet throws away 
Table 1

Structure of the test phase in the three conditions.

\begin{tabular}{|c|c|c|}
\hline \multicolumn{3}{|l|}{ Condition } \\
\hline Child & Third party & Control \\
\hline \multicolumn{3}{|l|}{ Phase 1} \\
\hline $\begin{array}{l}\text { E2 introduces object } \\
\text { to child: "This is } \\
\text { YOUR hat. Look } \\
\text { how nice it is". }\end{array}$ & $\begin{array}{l}\text { E2 introduces } \\
\text { object to child: } \\
\text { "This is MY hat. } \\
\text { Look how nice it is". }\end{array}$ & $\begin{array}{l}\text { Puppet introduces } \\
\text { object to child: "This } \\
\text { is MY hat. Look how } \\
\text { nice it is". }\end{array}$ \\
\hline \multicolumn{3}{|c|}{ Phase 2} \\
\hline \multicolumn{3}{|c|}{$\begin{array}{l}\text { Puppet to child: "I take my bag, take the hat and put it in my bag". } \\
\text { While saying it the puppet moves the bag close to the child and puts } \\
\text { the hat into his bag }\end{array}$} \\
\hline \multicolumn{3}{|c|}{ Phase 3} \\
\hline \multicolumn{3}{|c|}{$\begin{array}{l}\text { Puppet to child: "Actually, I do not like this hat anymore. I will } \\
\text { throw it away". }\end{array}$} \\
\hline \multicolumn{3}{|c|}{$\begin{array}{l}\text { While saying this the puppet takes the object out of the bag and } \\
\text { throws it into the trash }\end{array}$} \\
\hline
\end{tabular}

the object. The latter two phases were basically identical across conditions - the only relevant difference between conditions was in who was identified as the owner in the first phase (see Table 1).

The first phase varied across conditions. In the Child condition, E2 showed the child's piece of clothing to the child and said "this is your hat". The child typically confirmed that the object was indeed his/her hat and E2 then commented on the nice features of the object. Then E2 put the object on the table on the opposite side of the child and said "I put it here for now. I have to read something now. See you in a bit." and turned away from the child pretending to read something. During the introduction of the object, E1 was bent down and stayed quiet and the puppet was below the table out of sight. After E2 verbally announced that she was disengaging from the interaction, E1 came to life and the puppet appeared on the scene. In the Third-party condition, the procedure was virtually identical except that at the appropriate moment E2 showed her own hat to the child and said "this is my hat". In the Control condition, the procedure was again highly similar except that the puppet had to be activated earlier in the scene in order to identify his piece of clothing. Thus, in this condition E2 simply stayed turned, reading, all the time and the puppet himself introduced his own hat to the child saying "this is my hat" and then proceeded as in the other conditions. In this condition E1 would stayed engaged with the child throughout.

The second phase was identical for all conditions, except for minor wording differences necessary for the different conditions. Thus, in the Child and Third-party conditions, the puppet said, e.g., "Oh, what is this? A hat. Nice." Then the puppet moved the paper bag closer to the child, saying "I take my bag, I take the hat and put it in my bag". While saying this, the puppet took the hat and slowly put it into his bag. In the Control condition, the puppet would directly say "I take my bag...", given that he introduced the hat to the child and so cannot be surprised by its presence on the table.

The third phase was identical for all conditions. Once the object had entered the bag, the puppet said "Actually, I don't like this hat anymore. I'll throw it away". As he was saying this, the puppet took the object out of the bag and began to throw it into the trash, slowly.

It should be noted that in the second and third phases, the voice of the puppet would always sound cheerful and friendly and he would act as if he was entitled to take possession of the object on the table and to throw it in the trash. The rationale was that the child was not supposed to react to features such as sneakiness or mean intentions of the character, often associated with stealing. In the second phase, for example, the puppet acted as if he did not know that he was illegitimately taking away an object. Given what he already experienced in the warm up, the puppet acted as if the objects on the table did not belong to anyone, as if they had been abandoned, and he could take them for himself. This is also the reason why the second phase is called "taking away" rather than "stealing".

\subsection{Coding and reliability}

\subsubsection{Warm-up phase}

Children's interventions during the warm up phase in which the puppet would make instrumental mistakes were coded in the following way:

(a) Verbal correction: Child intervenes verbally to correct the puppet (e.g., "you have to turn it"; "no, the other way").

(b) Correction through demonstration: Child demonstrates to the puppet how to use the instrument properly (e.g., saying "like this" and then showing the correct use).

For each of the four objects used to make an instrumental mistake, it was coded whether (and how often) children produced such interventions.

\subsubsection{Test phase}

In the test phase, the measure of children's understanding of property rights was protest, divided into five different levels, in terms of their normative strength:

(1) Explicitly normative protest: Child intervenes against the puppet's act, making use of explicit normative vocabulary (e.g., "You must not do that").

(2) Imperative protest: Child intervenes against the puppet's act making use of imperative vocabulary (e.g., "Leave the hat on the table") or using negations plus possessive protest (e.g., "No, it is mine", "No, it is hers" pointing towards E2).

(3) Simple possessive protest: Child intervenes against the puppet's act making use of possessive pronouns or naming the owner of the object (e.g., "Mine", "It is yours", pointing towards E2 and saying "It is from her" or "It is from Mrs.") Simple protest: Child intervenes against the puppet's by saying no (e.g.,"No").

(4) Indirect protest: Child intervenes against the puppet's act by producing utterances that indirectly indicate that the act is problematic (e.g., "Your mum gets angry"; "the bin is for the trash").

(5) Physical protest: Child tries to grab object from puppet's hands. 
All instances of protest were coded, but only the highest level of protest occurring in each phase of each condition was considered for the proportions of different protest types represented in Figs. 1a and 1b (e.g., if a child produced physical protest, simple protest and normative protest during a trial, the final coding for that trial would be only normative protest).

Children's protest was coded for each phase as follows:

- Second phase: from the moment the puppet appears on the scene and notices the new object on the table until the object enters the bag.

- Third phase: from the moment the puppet says that he does not like the object anymore until the object enters the trash can.

Anything occurring after those phases, including possible tattling by the child when E2 would newly orient towards the child, was not included in the coding.

All sessions were videotaped with two cameras and coded by two observers. Observer 1 coded 44 children,
22 2-year-olds and 22 3-year-olds. Observer 2 coded the remaining 16 children, eight 2-year-olds and 83 -year-olds. A third independent observer, Observer 3, coded a random sample of $20 \%$ of the children for inter-rater reliability $(n=18), 20 \%$ of the children coded by Observer $1(n=14)$, and $20 \%$ of the children coded by Observer $2(n=4)$. Because of the ordinal ratings, Cohen's weighted Kappa (Fleiss \& Cohen, 1973) was calculated for the protest measures. There was almost perfect agreement between Observer 1 and Observer $3(k=0.948)$ and perfect agreement between Observer 2 and Observer $3(k=1)$.

\subsection{Statistical analysis}

To analyze the data, we used a Generalized Linear Mixed Model (GLMM; Baayen, 2008). Into this, we initially included the three factors of interest (AGE, PHASE and CONDITION) and all their interactions up to the highest order, as well as three factors potentially confounding the results (GENDER, ORDER in which conditions were presented, and TRIAL, i.e. whether it was the first or second

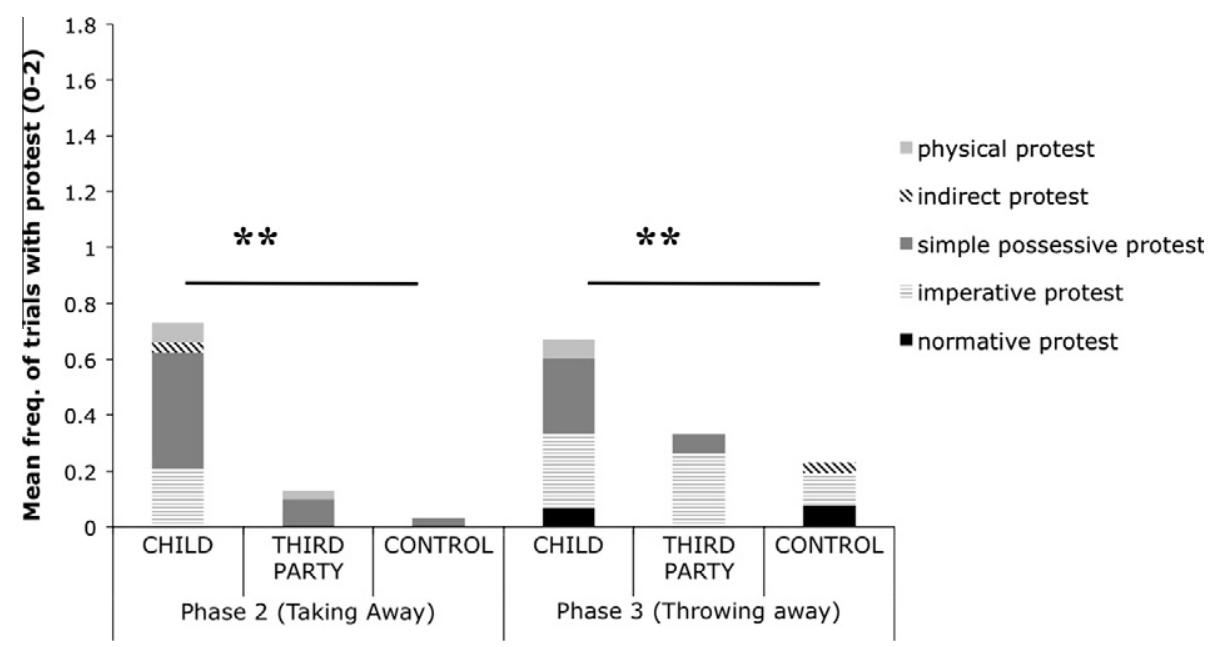

Fig. 1a. Mean frequencies of trials with protest by phase and condition in 2-year-olds.

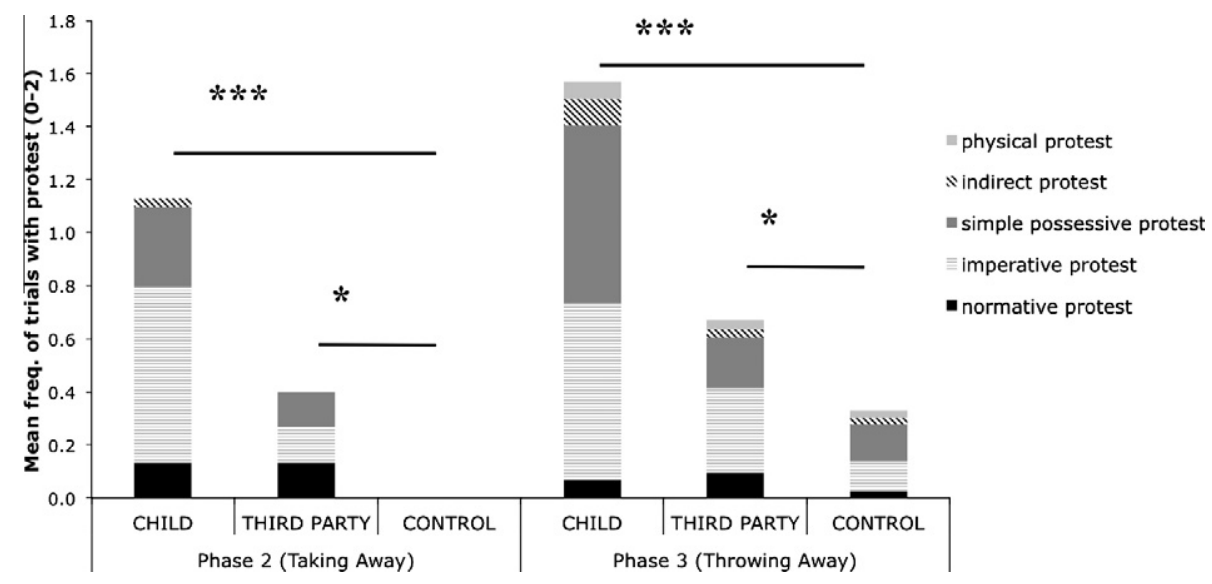

Fig. 1b. Mean frequencies of trials with protest by phase and condition in 3-year-olds. 
trial of the same condition in the same phase) as fixed effects, and child ID as a random effect. The response was binary indicating whether the child protested or not in a given trial. Since none of the potential confounds was significant (all $p>.16$ ) we removed them from the model.

Initially, we tested the full model comprising the three factors of interest, their interactions and the random effect with a null model comprising only the random effect using a likelihood ratio test (Dobson, 2002). Once this revealed significance, we inspected the significance of the individual interactions and main effects, beginning with the threeway interaction. When this was not significant, we removed it from the model and inspected the two-way interactions' significances.

We ran the models in $R$ (version 2.12.1, Development Core Team, 2010) using the function lmer of the package lme4 (Bates \& Maechler, 2010). We used a binomial error structure and logit link function and estimated coefficients using Maximum Likelihood. Likelihood ratio tests were conducted using the $R$-function Anova. $P$-values of individual interaction or main effects were either derived using likelihood ratio tests comparing a model with and without the effect to be tested or those provided by the output of the function lmer. We then ran post hoc Wilcoxon tests for each phase and age to locate the source of the differences more precisely.

\section{Results}

\subsection{Main analyses}

The mean frequencies of the occurrence of any form of protest in each condition are reported in Table 2 for phase 2 (taking away) and phase 3 (throwing away), where $N$ indicates the number of infants, by age, who protested at least once in each condition.

The mean frequencies of the different kinds of protest in both target phases in the different conditions are depicted in Figs. $1 \mathrm{a}$ and $1 \mathrm{~b}$.

In a first analysis, all kinds of protest were included in a GLMM model. Overall, the three factors (AGE, PHASE and CONDITION) had a marked influence on protesting (likelihood ratio test, $\operatorname{LR}(11)=220.1, p<.001)$. The three-way interaction between AGE, PHASE and CONDITION was not significant $(\operatorname{LR}(2)=2.7, p=.26)$, but all two-way interactions were (AGE and PHASE: $z=2.397, p=.016$; AGE and CONDITION: $\operatorname{LR}(2)=7.067, p=.029$; PHASE and CONDITION: $\operatorname{LR}(2)=11.3, p=.004)$.

Given the significance of the two-way interactions, post hoc Wilcoxon tests were used to locate the source of these differences more precisely and to investigate whether a sensitivity to violations of property rights was observable looking at each phase and each age. For 2-year-olds, in the second phase (puppet putting object in his bag) children protested more in the Child condition than in either of the other two conditions (Third Party condition $(Z=-3.14, p<.01)$; Control condition $(Z=-3.39, p<.01))$, with no difference between the Third Party and Control conditions $(Z=-1.34, p=.180)$. Similarly, the 2-year-olds in the third phase (puppet throwing object away) protested more in the Child condition than in the other two conditions (Third Party condition $(Z=-2.35, p<.05)$; Control condition $(Z=-2.59, p<.01)$, with no difference between the Third Party and Control conditions $(Z=-0.91$, $p=.366)$.

The 3-year-olds behaved differently. In the second phase, they again protested against the puppet putting the object into his bag more often in the Child condition than in either of the other two conditions (Third Party condition $(Z=-3.74, p<.001)$; Control condition $(Z=-4.16$, $p<.001))$. Crucially, however, in contrast to the 2 -yearolds, 3-year-olds protested more in the Third Party condition than in the Control condition $(Z=-2.64, p<.01)$, showing their application of the ownership norm even in situations not directly involving themselves. In the third phase 3-year-olds again protested against throwing away the object more often in the Child condition than in either of the other two conditions (Third Party condition $(Z=-4.07, \quad p<.001)$; Control condition $(Z=-4.33$, $p<.001)$ ). But again, unlike the 2-year-olds, they also protested more against throwing the object away in the Third Party than in the Control condition $(Z=-2.00, p<.05)$.

To make absolutely certain that children were protesting in a truly normative way, we re-did these analyses using a stricter criterion for protest in which we excluded indirect and physical protest because of their potentially ambiguous nature (even though these occurred only around $4-5 \%$ of the time each, as can be seen in Figs. 1a and 1b). Using only the three clearest protest categories (explicit, imperative, and possessive protest) we re-ran the GLMM model. Overall, the three factors had a marked influence on protesting (likelihood ratio test, $\operatorname{LR}(11)=188.1, p<0.001)$. The three-way interaction between AGE, PHASE and CONDITION was not significant $(\operatorname{LR}(2)=3.7, p=.15)$, but all two-way interactions were or tended to be (AGE and PHASE: $Z=1.66, p=.098$; AGE and CONDITION: $\operatorname{LR}(2)=6.42, p=.040$; PHASE and CONDITION: $\operatorname{LR}(2)=8.3, p=.0157)$.

Post hoc Wilcoxon tests were used to locate the source of these differences more precisely. For 2-year-olds, in the second phase (puppet putting object in his bag) children protested more in the Child condition than in either

Table 2

Mean sum score of protest per condition by age during phases 2 and 3, SD and number of infants who protested at least once during each condition.

\begin{tabular}{|c|c|c|c|c|c|c|c|c|c|c|c|c|c|c|c|c|c|c|}
\hline \multirow[t]{3}{*}{ Age } & \multicolumn{9}{|c|}{ Phase 2 (taking away) } & \multicolumn{9}{|c|}{ Phase 3 (throwing away) } \\
\hline & \multicolumn{3}{|l|}{ Child } & \multicolumn{3}{|c|}{ Third party } & \multicolumn{3}{|c|}{ Control } & \multicolumn{3}{|l|}{ Child } & \multicolumn{3}{|c|}{ Third party } & \multicolumn{3}{|c|}{ Control } \\
\hline & Mean & $S D$ & $N$ & Mean & $S D$ & $N$ & Mean & $S D$ & $N$ & Mean & $S D$ & $N$ & Mean & $S D$ & $N$ & Mean & $S D$ & $N$ \\
\hline 2 & 0.73 & 0.83 & 15 & 0.13 & 0.35 & 4 & 0.03 & 0.18 & 1 & 0.67 & 0.84 & 13 & 0.33 & 0.66 & 7 & 0.23 & 0.57 & 5 \\
\hline 3 & 1.13 & 0.86 & 21 & 0.30 & 0.60 & 7 & 0 & 0 & 0 & 1.57 & 0.63 & 28 & 0.70 & 0.75 & 16 & 0.40 & 0.67 & 9 \\
\hline
\end{tabular}


of the other two conditions (Third Party condition $(Z=-3.00, p<.01)$; Control condition $(Z=-3.29, p<.01))$, with no difference between the Third Party and Control conditions $(Z=-1.00, p=.317)$. In the third phase (puppet throwing object away) the 2-year-olds protested more in the Child condition than in the Control condition $(Z=-2.65, p<.01)$, but there was no difference between Child and Third Party condition $(Z=-1.72, p=.085)$ nor between the Third Party and the Control condition $(Z=-1.27, p=.206)$.

The 3-year-olds behaved differently. In the second phase, they again protested against the puppet putting the object in his bag more often in the Child condition than in either of the other two conditions (Third Party condition $(Z=-3.62, \quad p<.001)$; Control condition $(Z=-4.14$, $p<.001)$ ). Crucially, however, in contrast to the 2-yearolds, 3-year-olds protested more in the Third Party condition than in the Control condition $(Z=-2.64, p<.01)$, showing their application of the ownership norm even in situations not directly involving themselves. In the third phase 3-year-olds again protested against throwing away the object more often in the Child condition than in either of the other two conditions (Third Party condition $(Z=-3.74, \quad p<.001)$; Control condition $(Z=-4.24$, $p<.001)$ ). But again, unlike the 2 -year-olds, they also protested more against throwing the object away in the Third Party than in the Control condition $(Z=-2.00, p<.05)$.

Overall, then, while children of both ages protested especially frequently when their own piece of clothing was taken or thrown into the trash, the 3-year-olds, but not the 2-year-olds, protested more when the puppet attempted to take or throw into the trash a third party's piece of clothing than when he did the same with his own piece of clothing. There were no gender effects, no effects related to the order in which the conditions were presented and no cumulative effects over trials. Threeyear-olds seem to understand norms of property in an agent-neutral way.

\subsubsection{Additional analyses}

In the warm-up phase, practically all children (29 of the 30 2-year-olds and all of the 303 -year-olds) intervened towards the puppet at least once during the warm up phase. 3-year-olds $(M=3.57, S D=.77)$ protested significantly more often than 2-year-olds $(M=2.97, \quad S D=1.07$; $t(58)=-2.49, p<.05)$. Their protest during the warm up was also of a different kind, on a more verbal level. While $74 \%$ of protests by 2 -year-olds were corrections through demonstrations, only $31 \%$ of 3 -year-olds protests were of that kind $(t(58)=3.32, p<.001)$. The remaining protests were verbal corrections.

Moreover, there was a significant correlation between protest in the warm up and protest in the test phase for 2 -year-olds $(r=.455, p<.05)$ while there was no correlation for 3-year-olds $(r=.006, p=.977)$.

\section{Discussion}

Almost all previous studies of children's understanding of property rights have used imaginary stories and verbal interviews. In the current study, we had children directly involved in interactions involving property rights violations and they could respond potentially nonverbally, which opened up the possibility that even 2-year-old children might show some understanding. At the same time, we used a fairly demanding measure of property understanding, requiring children to actively protest against property rights violations involving third parties.

We found that even in the most generous analysis in which nonverbal interventions to property rights violations were counted, 2-year-olds did not stand up for the property rights of a third party. And it was not that children this young are too shy in general to stand up to a puppet operated by an adult. They protested reasonably frequently when their own property was either taken from them or thrown away - several times more often than when anyone else's property was similarly taken or thrown away. It is nevertheless possible, of course, that the 2-year-olds appreciated that a third party's property rights were being violated, but just did not care as much as they did about their own property.

In contrast to these findings with 2-year-olds, children at around their third birthday protested when the puppet either took or threatened to throw away the property of any other person. Even though the 3-year-olds protested most often when their own item of clothing was taken or thrown away, they still protested more often when a puppet took or threw away a third party's clothing than when the puppet did this (legitimately) to his own clothing in the control condition. And in staging this protest, the 3-yearolds reasonably often used normative language stating such things as "You can't do that. Its hers." Standing up for the property rights of a third party, using normative justifications on occasion, demonstrates - more clearly and at a younger age than any previous study - young children's emerging understanding of the normative dimension of property as it applies to all persons equally in an agent-neutral manner. It is not just that I do not like it when someone takes or throws away an object that doesn't belong to them; it is wrong.

Interestingly, not only did 3-year-olds know that taking someone else's object is a violation of their property rights, they also knew that throwing away someone else's object is also a violation of those rights. We were worried initially that in the third phase of the experiment, children would protest indiscriminately when the puppet wanted to throw away a perfectly good object; after all, their parents almost certainly would object to their throwing away any perfectly good object, even their own. However, this was not the case. Although children of both ages protested occasionally when the puppet wanted to throw away his own object, the 3-year-olds protested much more often when he wanted to throw away someone else's object. To our knowledge, this is the first demonstration of young children's understanding of the property right permitting an owner to discard his own object but not someone else's.

These results may be limited by our limited selection of objects (clothes) and a limited variety of third parties (puppet strangers). It is an interesting question for future research how general the pattern of normative responses found here is: will children respond differently, for 
example, when friends or relatives are involved (if anything, we would expect the pattern to be stronger)? And would they intervene in similar or different ways when other types of objects are involved? Here it might well be that clothes are special as they are paradigmatic examples of personal items for young children and with which children have much everyday experience. In addition, we used only two types of property-relevant actions on objects taking away and throwing away - and the property of the objects was simply established without any property transformations involved. Whether our results generalize to other property-relevant actions and when property is established in different ways are questions for future research.

It is still not clear how children's concept of property develops. Thus, children might start out with an understanding of some paradigmatic "conditions of ownership" rules (e.g., by distinguishing between gift-giving and lending) and some paradigmatic "implications of ownership" rules (e.g., pertaining to taking, disposing of, using etc.), and subsequently enrich this conceptual core by incorporating more complex rules of both kinds. Regardless, however, of which aspects of property children understand initially, the present finding is that by 3 years of age, children have some understanding of the basic normative structure of property and property rights violations. Taken together with previous work on children's understanding of games, both pretence and rule games (Rakoczy, 2008; Rakoczy et al., 2008), the present study thus presents converging evidence that already at this age children are becoming "status conscious" (Kalish, 2005) in the sense that they are beginning to understand that a social collective may confer special status on an object, either temporarily and ad hoc as in pretense (e.g., this stick is a horse), or else on a more permanent and principled basis as in property assignment.

But again we must emphasize there is still much to be learned, as lawyers argue in court everyday about the fundamentals of property, property rights, and property rights violations. Interestingly, Kalish (2005) discusses the possibility that children begin first to understand the normative dimension of things in a naïvely realistic way (e.g., that just like a ball is objectively round, it is objectively "Jeffrey's") without understanding anything about conventionality (the fact that, e.g., property exists only due to the collective practices that create it). It might thus be that the 3-yearold children in our study, though already understanding, respecting, and enforcing property rights, have as yet no insight into their man-made nature. Future research will thus have to investigate the development of this understanding of the conventionality and normativity of the constitutive rules that constitute the institution of human property.

In current analyses of the evolution of human cooperation and culture, social norms play an extremely prominent role (e.g., Chudek \& Henrich, 2011; Tomasello, 2009). In the current study, children stood up for the property rights of third parties, showing an identification with the groups' creation and enforcement of the social norms defining property. This emerging group-mindedness will play an important role as children not only become conventional and moral beings themselves, but as they insist that others in their group be conventional and moral beings as well.

\section{Acknowledgements}

We would like to thank all the day-care centres and children for their cooperation. We are particularly grateful to Elena Rossi, Gesa Volland, Katja Kirsche, Anne Herbik, Yvonne Naumann-Sparschuh, Eva Kilchert and Maria Baumeister for assistance in testing and coding. Thanks also to Roger Mundry for statistical advice.

\section{References}

Baayen, R. H. (2008). Analyzing linguistic data. Cambridge: Cambridge University Press.

Bakeman, R., \& Brownlee, J. R. (1982). Social rules governing object conflicts in toddlers and preschoolers. In K. H. Rubin \& H. S. Ross (Eds.), Peer relationships and social skills in childhood (pp. 99-111). New York: Springer-Verlag.

Bates, D., \& Maechler, M. (2010). Ime4: Linear mixed-effects models using S4 classes. R package version 0.999375-37.

Blake, P. R., \& Harris, P. L. (2009). Children's understanding of ownership transfers. Cognitive Development, 24(2), 133-145.

Brenner, J., \& Mueller, E. (1982). Shared meaning in boy toddlers' peer relations. Child Development, 53(2), 380-391.

Bronson, W. C. (1975). Developments in behavior with age mates during the second year of life. In M. Lewis \& L. A. Rosenblum (Eds.), Friendship and peer relations (pp. 131-152). New York: Wiley.

Chudek, M., \& Henrich, J. (2011). Culture-gene coevolution, normpsychology and the emergence of human prosociality. Trends in Cognitive Sciences, 15(5), 218-226.

Dawe, H. C. (1934). An analysis of two hundred quarrels of preschool children. Child Development, 5, 139-157.

Dobson, A. J. (2002). An introduction to generalized linear models. Boca Raton: Chapman \& Hall/CRC.

Dunn, J., \& Munn, P. (1987). Development of justification in disputes with mother and sibling. Developmental Psychology, 23(6), 791-798.

Fasig, L. E. (2000). Toddlers' understanding of ownership: Implications for self-concept development. Social Development, 9(3), 370-382.

Fleiss, J. L., \& Cohen, J. (1973). The equivalence of weighted kappa and the intraclass correlation coefficient as measures of reliability. Educational and Psychological Measurement, 33(3), 613-619.

Friedman, O., \& Neary, K. R. (2008). Determining who owns what: Do children infer ownership from first possession? Cognition, 107, 829-849.

Hay, D. F. (1984). Social conflict in early childhood. In G. Whitehurst (Ed.). Annals of child development (Vol. 1, pp. 1-44). Greenwich, CT: Jai Press.

Hay, D. F. (2006). Yours and mine: Toddlers' talk about possessions with familiar peers. British Journal of Developmental Psychology, 24(1), 39-52.

Hay, D. F., \& Ross, H. S. (1982). The social nature of early conflict. Child Development, 53(1), 105-113.

Hook, J. (1993). Judgments about the right to property from preschool to adulthood. Law and Human Behaviour, 17(1), 135-146.

Kalish, C. (2005). Becoming status conscious: Children's appreciation of social reality. Philosophical Explorations, 8(3), 245-263.

Kangiesser, P., Gjersoe, N., \& Hood, B. M. (2010). The effect of creative labor on property-ownership transfer by preschool children and adults. Psychological Science, 21(9), 1236-1241.

Kim, S., \& Kalish, C. W. (2009). Children's ascriptions of property rights with changes of ownership. Cognitive Development, 24(3), 322-336.

Nagel, T. (1986). The view from nowhere. New York: Oxford University Press.

Neary, K. R., Friedman, O., \& Burnstein, C. L. (2009). Preschoolers infer ownership from "control of permission". Developmental Psychology, 45(3), 873-876.

R Development Core Team (2010). R: A language and environment for statistical computing. Vienna, Austria: R Foundation for Statistical Computing.

Rakoczy, H. (2008). Taking fiction seriously: Young children understand the normative structure of joint pretend games. Developmental Psychology, 44(4), 1195-1201. 
Rakoczy, H., \& Tomasello, M. (2009). Done wrong or said wrong? Young children understand the normative directions of fit of different speech acts. Cognition, 13(2), 205-212.

Rakoczy, H., Warneken, F., \& Tomasello, M. (2008). The sources of normativity: Young children's awareness of the normative structure of games. Developmental Psychology, 44(3), 875-881.

Rakoczy, H., Warneken, F., \& Tomasello, M. (2009). Young children's selective learning of rule games from reliable and unreliable models. Cognitive Development, 24, 61-69.

Rose, C. M. (1985). Possession as the origin of property. The University of Chicago Law Review, 52(1), 73-88.

Ross, H. S. (1996). Negotiating principles of entitlement in sibling property disputes. Developmental Psychology, 32(1), 90-101.

Searle, J. R. (1995). The construction of social reality. London: Allen Lane.

Shantz, C. U. (1987). Conflicts between children. Child Development, 58, 283-305.
Snare, F. (1972). The concept of property. American Philosophical Quarterly, 9(2), 200-206.

Tisak, M. S., \& Turiel, E. (1984). Children's conceptions of moral and prudential rules. Child Development, 55(3), 1030-1039.

Tomasello, M. (1998). One child's early talk about possession. In J. Newman (Ed.), The linguistic of giving (pp. 349-373). Philadephia: John Benjamins.

Tomasello, M. (2009). Why we cooperate. Cambridge, MA: The MIT Press.

Vaish, A., Missana, M., \& Tomasello, M. (2011). Three-year-old children intervene in third-party moral transgression. British Journal of Developmental Psychology, 29(1), 124-130.

Wyman, E., Rakoczy, H., \& Tomasello, M. (2009). Normativity and context in young children's pretend play. Cognitive Development, 24(2), 146-155. 